\title{
O PRINCÍPIO CRÍTICO-MATERIAL DA ÉTICA DA LIBERTAÇÃO
}

\section{JOSE EDEMILSON PEREIRA DOS ANJOS ${ }^{1}$}

RESUMO: O artigo apresenta um estudo teórico e bibliográfico acerca do critério e princípio crítico-material da Ética da Libertação de Enrique Dussel. Situa o surgimento da Ética da Libertação no contexto filosófico imediatamente posterior ao debate entre a Filosofia latinoamericana e da Libertação com a Ética do Discurso, iniciado a partir do ano de 1989. Mostra a transformação ocorrida no aporte teórico e categorial na filosofia de Dussel, resultante da maneira crítica, criativa e pessoal com que soube lidar com a influência marcante de três grandes filósofos críticos da modernidade: E. Lévinas, K. Marx e K.-O. Apel. O estudo busca aprofundar o conhecimento acerca do tema "o critério e princípio crítico-material da Ética da Libertação", destacando a "vítima" como categoria-chave da crítica, bem como a centralidade e a relevância do aspecto material-negativo (representada na figura da "vítima") para a arquitetônica da referida Ética. Ao longo de seu desenvolvimento, descobre a vida humana concreta como o âmbito próprio de ação da razão ético-crítica, que reconhece a negatividade da vítima como o ponto de partida da crítica; também serão trabalhados alguns conceitos-chave, tais como "vítima", "responsabilidade", "ética material”, "intersubjetividade".

PALAVRAS-CHAVE: Filosofia da Libertação. Enrique Dussel. Razão ético-crítica. Vítimas.

ABSTRACT: The article presents a theoretical and bibliographical study about the criterion and critical-material principle from Ethics of Liberation of Enrique Dussel. It situates the emergence of the Ethics of Liberation in the philosophical context immediately after the debate between Latin American Philosophy and the Liberation with Ethics of Discourse, which began in 1989. It shows the transformation that occurred in the theorical and categorical contribution in Dussel's philosophy, resulting from the critical, creative and personal way he handled the remarkable influence of three great critics of the modernity philosophers: E. Lévinas, K. Marx and K.-O. Apel. The study seeks to deepen the knowledge on the theme "the criterion and critical-material principle of the Ethics of Liberation", highlighting the "victim" as a key category of criticism, as well as the centrality and the relevance of the material-negative aspect (represented in 'victm's figure) to the architectonic of the referred Ethics. Throughout its development, it reveals the concrete human life as the proper field of action of ethical-critical reasoning, which recognizes the negativity of the victim as the starting point of criticism; Key concepts such as "victim", "responsibility", "material ethics", "intersubjectivity" will also be addressed.

KEYWORDS: Philosophy of Liberation. Enrique Dussel. Ethical-critical reason. Victims.

\footnotetext{
1 Mestre em Educação e Contemporaneidade e estudante do curso de doutorado em Educação e Contemporaneidade, vinculado ao Programa de Pós-graduação em Educação e Contemporaneidade (PPGEduC) da Universidade do Estado da Bahia (UNEB). E-mail: j.edemilson@live.com. Este trabalho integra, de maneira parcial, o processo de pesquisa teórica, de abordagem qualitativa e procedimento bibliográfico, em desenvolvimento como processo formativo, com o apoio financeiro da CAPES, no Doutorado Acadêmico vinculado ao Programa de Pós-Graduação em Educação e Contemporaneidade (PPGEduC) da Universidade do Estado da Bahia (UNEB).
} 
Duas décadas após a construção de sua primeira Ética (década de 1970), Enrique Dussel publica, em 1998, a Ética da Libertação. Ao contrário do primeiro projeto, comprometido com a construção de uma Ética latino-americana, como um empenho de crítica hermenêutica elaborada a partir da exterioridade do continente (sua história, seus povos, suas culturas, sua religiosidade, suas gestas) a Ética da Libertação surge com renovada arquitetônica teórica e categorial e uma pretensão ético-crítica a partir da perspectiva mundial, ao considerar o contexto de globalização e exclusão em escala planetária.

À luz do critério e do princípio material, descobre-se a existência de vítimas. Sua existência revela uma contradição performativa no interior do projeto utópico do sistema vigente: a maioria dos participantes se encontra como afetados ou privados da possibilidade de cumprir com as exigências mínimas de sobrevivência, indicadas pelo próprio sistema como direitos.

A existência inevitável da vítima, enquanto negatividade-crítica, é o critério de falsificação da verdade do sistema hegemônico, por meio do qual será julgado como nãoverdadeiro (devido ao não cumprimento do critério material), como não-válido (por não cumprir o princípio formal intersubjetivo ao ter excluído as vítimas - afetadas no presente ou no futuro - da comunidade de argumentação), como não-eficaz (por não reunir as condições e possibilidade objetivas minimamente exigidas para assegurar a vida da vítima).

A crítica provoca a inversão por meio da qual a eticidade vigente (o "Bem") - agora desde a perspectiva daqueles que foram afetados ou privados do acesso às mediações necessárias ao cumprimento das condições do critério material universal, no sentido da produção, reprodução e desenvolvimento da vida - tem revelada a sua face oculta (seu mito irracional) e aparece como ilegítima (o "mal”). Esta inversão crítica, possível a partir da perspectiva da vítima, torna viável a desconstrução do sistema hegemônico.

Desse modo, a Ética da Libertação corrobora a sua posição crítica - seja em razão de seu conteúdo (material, ao considerar a produção, reprodução e desenvolvimento da vida humana) seja em decorrência da negatividade de sua perspectiva (o reconhecimento da existência da vítima como "outro") -, a partir da qual julga a "eticidade" vigente (sistema hegemônico) como causa originária da vítima, ao mesmo tempo em que contribui para a consolidação da posição da Filosofia da Libertação enquanto expressão filosófica mundial.

Para este trabalho, a Ética da Libertação se constitui no horizonte teórico e categorial no interior do qual foi desenvolvido o presente trabalho. Situado no momento propriamente crítico da Ética da Libertação - "material" e "negativo" - descobre-se a vida humana concreta 
do sujeito ético como o âmbito próprio da razão ético-crítica. Além do aspecto "material" (relativo à verdade prática), o ético-crítico implica, também, os aspectos formal (relativo à validez intersubjetiva) e de factibilidade (relativo à eficácia). Importa ressaltar, entretanto, que o presente trabalho se limita, em razão do recorte temático, apenas à análise do aspecto éticocrítico material.

Neste sentido, o presente estudo busca aprofundar o conhecimento acerca do critério e princípio crítico-material da Ética da Libertação e, a partir deste tema, destacar a "vítima" como categoria-chave da crítica, bem como a centralidade e a relevância do aspecto material-negativo (representado na figura da "vítima") para a sua arquitetônica.

\section{Uma Ética da vida: ética crítica a partir das vítimas}

A Ética da Libertação de Enrique Dussel tem como um de seus marcos referenciais mais significativos a Ética do Discurso, a partir do diálogo filosófico, iniciado em 1989, com os filósofos Karl-Otto Apel e Jürgen Habermas, realizado no contexto do Programa de Diálogo Filosófico Norte-Sul² (DUSSEL, 2005; 1994a; SIDEKUM, 1994). Desde então, inaugura-se uma nova fase na produção intelectual de Dussel, como pode ser notado na transformação do aporte teórico e categorial de sua filosofia, sob a influência, principalmente, do referencial teórico marxiano ${ }^{3}$ (na elaboração de uma econômica ${ }^{4}$ com maior profundidade e precisão) e da pragmática, de K.-O. Apel: ocorre, por um lado, a incorporação de novos temas, com nova abordagem a partir da perspectiva da filosofia contemporânea; e, por outro, a ampliação do alcance de sua Ética, que, a partir da perspectiva de uma mundialidade planetária, aborda os desafios da humanidade em uma época de globalização e exclusão.

Nesta época, em face do avanço da influência pós-moderna - com suas diversas matizes de conservadorismo, ceticismo e cinismo (DUSSEL, 1993c) -, o giro pragmático-linguístico

\footnotetext{
${ }^{2}$ No ano de 1989, terá início um ciclo de debates entre filósofos da libertação e filósofos vinculados ao giro pragmático-linguístico, dentre os quais, principalmente, Karl-Otto Apel e Jürgen Habermas, além de Paul Ricoeur, Richad Rorty e Gianni Vattimo, no contexto do Programa de Diálogo Filosófico Norte-Sul, coordenado, entre outros, por Raúl Fornet-Betancourt.

3 “Teníamos, por primera vez en la historia de la filosofía, una visión de conjunto de Marx. Ahora puede comenzarse la re-interpretación hermenéutica de su obra. Esto determinó un cambio en la arquitectónica categorial de nuestra filosofía de la liberación" (DUSSEL, 1993b, p. 146).

${ }^{4}$ Após o exílio no México, a partir de 1975, Dussel inicia um estudo sistemático das quatro edições da principal obra de Karl Marx, $O$ Capital. E apresenta quatro justificativas para este retorno a Marx: 1) explica o crescente empobrecimento da maioria dos povos latino-americanos; 2) com a finalidade de poder criticar o capitalismo enquanto causa do empobrecimento da maioria da humanidade do hemisfério Sul (África, Ásia e América Latina); 3) porque a Filosofia da Libertação deveria elaborar uma econômica e política firmes; e 4) para poder superar a interpretação standard marxista-leninista predominante na época (Dussel opta pela leitura direta dos originais de Marx, prescindindo da intermediação de seus comentadores clássicos). Cf. "Hermenéutica y liberación" (DUSSEL, 1993b) e “Autopercepción intelectual de un proceso histórico” (DUSSEL, 2018b).
} 
fornecerá elementos novos e promissores - criticamente confrontado com uma forte econômica - ao pensamento crítico de libertação elaborado a partir da periferia mundial (América Latina, África e Ásia) e que leva em consideração a sua realidade de pobreza e exclusão. Não obstante, Dussel criticará o paradigma da razão discursiva em decorrência do seu persistente formalismo (DUSSEL, 1994b). Ante a possibilidade objetiva, no plano empírico, da impossibilidade de argumentação (por dissenso ou exclusão assimétrica da vítima) na comunidade real de comunicação, o que torna ilegítima a validade formal intersubjetiva, Dussel critica a Ética do Discurso por não dispensar um tratamento adequado à problemática dos dominados e excluídos na comunidade real de vida (principium exclusionis ${ }^{5}$ ).

Neste sentido, concluirá que a pragmática permanece vazia de conteúdo material sem uma econômica; sem a qual, "son meras comunidades de comunicación o interpretación, sin corporalidad, carnalidad, sin subsumir en su reflexión el nível de la "vida"” (DUSSEL, 1993b, p. 150). Por isso, para a Ética da Libertação, a corporalidade sofredora (faminta, doente principium oppressionis ${ }^{6}$ ) será o "conteúdo" - da razão ético-crítica material no âmbito da produção, reprodução e desenvolvimento do sujeito ético como sujeito humano vivo - do atode-fala do "outro" como vítima.

Duas décadas após a publicação de Para una ética de la liberación latinoamericana coletânea composta de cinco tomos publicada entre os anos de 1973 e 1980 -, Enrique Dussel dará início, em 1993, à elaboração de sua segunda Ética (publicada em 1998 sob o título Ética de la liberación en la edad de la globalización y de la exclusión). Esta Ética da Libertação representa um segundo passo em relação àquele da década de 1970; não a substitui, "mas a atualiza reformando-a, radicalizando-a, desenvolvendo novos aspectos fundamentais e respondendo, aclarando ou se retratando diante das críticas feitas" (DUSSEL, 2012, p. 16).

Com relação à primeira, a Ética da Libertação (DUSSEL 2012; 1998) passa de uma (i) posição inspirada na positividade da exterioridade - enquanto "mundo" (em sentido heideggeriano) e "outro" (em sentido levinasiano) - para uma (ii) maior presença do "negativo" e do "material" e uma maior complexidade de sua arquitetônica baseada na racionalidade de princípios; de ser uma ética da libertação (iii) voltada à realidade latino-americana pretende

\footnotetext{
5 “Ahora es necesario referirnos, después del 'linguistic turn' y su transformación pragmática, al principium exclusionis: el Otro, como 'el afectado en la exterioridad', como el excluído 'de' la comunidad de comunicación o la Totalidad; es la alteridad propriamente dicha" (DUSSEL, 1994b, p. 147 - grifos do autor).

6 "La Ética de la Liberación denomina principium oppressionis el critério ético que considera al Otro como oprimido 'en' la Totalidad, como 'parte funcional' (no como 'sujeto') negada en sus intereses dis-tintos en el 'sistema'. Se trata del tema de la alienación propriamente dicha (la 'coisificación' del Otro)” (DUSSEL, 1994b, p. 146 - grifos do autor).
} 
situar-se no horizonte mundial planetário; (iv) além de ter ampliado e diversificado o seu referencial teórico.

\section{0 critério crítico material: a existência real de vítimas}

Para Dussel, o critério crítico-material da Ética da Libertação atua de maneira positiva quando descobre a existência do "outro" - reconhece-o. Para a consciência ético-crítica, todavia, o "outro" se revela como Outro. É a descoberta da existência do "outro" na negatividade da vítima.

A consciência da existência do "negativo" (neste caso, a negação do "outro") é o ponto de partida de toda a crítica; é "a relação que se produz entre a negação da corporalidade (Leiblichkeit), expressa no sofrimento das vítimas, dos dominados [...] e a tomada de consciência desta negatividade" (DUSSEL, 2012, p. 313). Neste sentido, a vítima se torna o ponto de partida da crítica:

Em primeiro lugar, abstrata e universalmente, o critério de criticidade ou critico (teórico, prático, pulsional, etc.) de toda norma, ato, microestrutura, instituição ou sistema de eticidade parte da existência real de 'vítimas', sejam por ora quais forem. É ‘criticável' o que não permite viver. (DUSSEL, 2012, p. 373).

O critério material crítico-positivo da Ética da Libertação implica o reconhecimento da existência real de vítimas e o tornar-se, consequentemente, responsável por esta vida negada, do "outro" como vítima. Tendo em conta a existência do "negativo", serão duas condições de possibilidade para o início do processo crítico (da razão ético-crítica):

A primeira condição de possibilidade da crítica é, então, o re-conhecimento da igualdade do outro sujeito, da vítima, mas a partir de uma dimensão específica: como vivente [...] A vítima é um vivente humano e tem exigências próprias não cumpridas na reprodução da sua vida no sistema. A re-sponsabilidade pelo outro, pela vítima como vítima, é igualmente condição de possibilidade, porque em sua origem o destituído não tem ainda capacidade para pôr-se de pé. A responsabilidade mútua (em primeiro lugar das outras vítimas), como veremos, é o segundo momento desta condição de possibilidade. (DUSSEL, 2012, p. 375 - grifos do autor)

Assim, a primeira destas condições implica, portanto, o reconhecimento da alteridade da "vítima", no modo preciso como indicado na metafísica - âmbito pré-ontológico - de Lévinas:

Não é possível a crítica ao sistema existente, sem o "re-conhecimento (Anerkennung)" do outro (da vítima) como sujeito autônomo, livre e dis-tinto (não só igual ou di-ferente). O "re-conhecimento" do Outro, graças ao exercício da razão ética pré-originária (da qual falamos acima), é anterior à crítica e anterior ao argumento (à razão discursiva ou dialógica); está na origem do processo e já é afirmação da vítima como sujeito, que é negada ou ignorada no 
sistema como sujeito - na definição luhmanniana de sistema o outro aparece como o mesmo: jamais como o outro sujeito. É a abertura à revelação do outro como interpelação aceita no sentido pré-ontológico de Lévinas." (DUSSEL, 2012, p. 374).

A segunda condição de possibilidade da crítica decorre, por sua vez, da ação desta razão ético-pré-originária - por meio da qual se reconhece o outro como "Outro" - e cobra responsabilidade (a certa altura, Dussel faz referência à imagem levinasiana do refém) pela "vítima". Neste sentido,

\begin{abstract}
A afirmação sobre a qual se recorta a negação crítica é, para repeti-lo pela última vez, o re-conhecimento da dignidade do sujeito autônomo do outro, como outro, e, simultaneamente, o tomá-lo a cargo e ficar situado como refém, como responsável pelo outro no sistema: "oferecendo a face" pelo outro, substitutivamente. A própria vítima, antes de tudo e quando é crítica, solidária e comunitariamente, re-conhece re-sponsavelmente as outras vítimas como vítimas. Nasce assim, antes da "interpelação" explícita, a comunidade crítica das vítimas. Mas este re-conhecimento re-sponsável, por sua vez, embora afirme o outro, o faz a partir de uma negatividade mais originária: o fato de ser vítima no sofrimento de sua corporalidade (negatividade material primeira). (DUSSEL, 2012, p. 376)
\end{abstract}

Na perspectiva teórica e categorial da Ética da Libertação, a "negatividade” adquire uma feição, particularmente, crítica como "vítima": "o critério da crítica é - para Dussel (2012, p. $375)$ - propriamente 'negativo'; é a descoberta da negatividade da vítima como vítima”. A tomada de consciência desta "negatividade" modifica a ética material, tornando-a crítica.

O critério ético-crítico é, portanto, "material" (quanto ao seu conteúdo) e "negativo" (com referência à negação da vida humana). Por "material" ", quer-se indicar o conteúdo mesmo da ética, neste caso, a própria realidade humana objetiva apreendida pela razão prático-material a partir do âmbito concreto das mediações ${ }^{8}$ necessárias à produção e reprodução de cada sujeito humano vivo. Dessa maneira, a ética material (de conteúdo) se apresenta em oposição à ética dita "formal" (que se ocupa das suas condições formais de validade). A noção de "negativo", por sua vez, faz referência à impossibilidade de produção, reprodução e desenvolvimento da vida de todos os sujeitos éticos participantes de uma comunidade de vida - sendo este impedimento a causa, ainda que não-intencional, do aparecimento da "vítima".

\footnotetext{
7 “Em alemão, Material (com 'a') significa 'material', como 'conteúdo (Inhalt)' oposto a 'formal'; enquanto materiell (com 'e') significa 'material', de matéria física, aposto, p. ex., a 'mental' ou 'espiritual'." (DUSSEL, 2012, p. 635 - Tese 10 - grifos do autor).

${ }^{8}$ Cf. em Dussel (1977), o capítulo 2 (“Da fenomenologia à libertação”), especificamente, o item 2.3.
} 
A "vítima" é o "outro" do sistema, em relação ao qual pode ser um oprimido ou um excluído. Seja como for, a sua existência é inevitável como consequência dos efeitos negativos não-intencionais de todo e qualquer sistema de "eticidade":

\begin{abstract}
Ahora se toma en cuenta que ningún acto (máxima, micro o macro-institución, etc.) puede pretender no tener algún efecto negativo, aunque sea no-intencional (como diría A. Smith); es decir, siendo imposible un acto perfecto sin ningún efecto negativo a corto o largo plazo (en último término teniendo en cuenta toda la historia universal), debe reconocerse inevitablemente (de manera apodídica) que alguien sufrirá el efecto negativo (aunque sea no-intencional) de dicho acto. Llamaremos víctima al que sufre tal negatividad. (DUSSEL, 2018b, p. 66 grifos do autor)
\end{abstract}

A criticidade do "negativo" se manifesta no processo de desconstrução do "já dado" (do ethos, norma, ação, instituição) por sua imperfeição, tendo em vista o porvir (a eticidade futura) como novo. Assim, uma ética é crítica quando, em face de um sistema de eticidade empírico, julga-o a partir da perspectiva das vítimas do referido sistema:

Las víctimas, por su mera existencia [...], juzgan al sistema vigente, al acto (máximo, micro o macro-institución, etc.) aún con "pretensión de bondade", como no-verdadero - como expresaba Adorno -, al no poder reproducir la vida de la víctima (negando así el cumplimiento del principio material); como noválido (al haber sido excluída la víctima de la discusión, negando el principio formal de validez); como no-factible (por el simple hecho de ser víctima el sistema no puede juzgarse como eficaz); es decir, desde la imposiblidad del cumplimiento de los dos anteriores principios). Las víctimas, desde el ejercício de una razón crítica universal (escéptica de la verdad vigente y dominadora, desde la perspectiva de la razón universal como crítica), constituyen una nueva comunidad de comunicación contra el sistema y la comunidad de dominación, ahora con validez crítica, y como actores históricos que luchan por la organización de um nuevo sistema más justo; que luchan por el reconocimiento de nuevos derechos. (DUSSEL, 2018b, p. 66 - grifos do autor)

A vítima se torna a perspectiva por meio da qual se opera a inversão (em função do exercício da razão ético-crítica) que favorece que o sistema de eticidade vigente - ingenuamente considerado como referência do "bem" e do "mal"; "ingenuidade cotidiana" que acomete não apenas a mentalidade pré-científica, mas também o "cidadão comum" e o cientista/especialista - seja criticado a partir de sua face perversa (como causa e origem da vítima), como um sistema "mau".

O critério negativo, material ou de conteúdo, é o próprio fato da impossibilidade de reproduzir a vida da vítima. Este aspecto material-negativo que afeta a vítima se reflete, graças à consciência crítica, sobre o sistema (norma, ação, instituição, etc.) e o "julga" a partir de seu resultado (a vítima) como não verdade, já que origina uma tal negatividade [...] A existência da vítima é sempre refutação material ou "falsificação" da verdade do sistema que a origina. (DUSSEL, 2012, p. 375). 
Para Dussel (1998), a crítica dirigida, a partir das vítimas, ao projeto utópico do sistema vigente é possível graças ao modo particular da Ética da Libertação se relacionar, através do duplo movimento de subsunção e negação, com a crítica moderna anterior. Por um lado, a Ética da Libertação subsume a crítica (de Marx, Nietzsche, Freud, Horkheimer, Benjamim, Adorno, Marcuse, Lévinas, dentre outros) aos aspectos de dominação da racionalidade moderna (razão instrumental dominadora) e, por outro - opondo-se ao irracionalismo de alguns destes críticos -, pode defender a universalidade da razão mesma. Esta subsunção e negação somente é possível porque a Ética da Libertação se situa material e negativamente a partir da exterioridade (da eticidade vigente, o projeto de "Bem" hegemônico válido), desde a alteridade da vítima (do outro como Outro).

\section{0 princípio ético-crítico: a negação ética de uma negação empírica}

O princípio ético-crítico se expressa, primeiramente, através do seu aspecto negativo (de maneira invertida em relação ao observado no critério), como juízo de constatação da impossibilidade de produção e reprodução da vida. Em um segundo momento, o aspecto positivo se manifesta como o compromisso responsável em favor do desenvolvimento da vida e com a transformação do sistema injusto.

O aspecto ético-crítico negativo é a presença do mal - não em seu sentido teológico, mítico, cabalístico ou escatológico, do confronto mal $X$ bem; nem no sentido do "mal originário" (do principium individuationis) presente em algumas correntes filosóficas. "Para a Ética da Libertação, ao contrário, a possibilidade do mal se encontra simplesmente na finitude humana: isto é, na impossibilidade de um conhecimento e de uma pulsão (amor) perfeitos" (DUSSEL, 2012, p. 376 - grifo do autor). E, por meio da inversão do argumento de Popper contra a impossibilidade do conhecimento perfeito, Dussel localiza a origem do mal no inexorável imperativo do indivíduo decidir-se - uma vez desamparado do auxílio da capacidade plena ou perfeita de mecanismos supra-humanos (o planejamento estatal, o mercado) ou pulsionais (como um impossível altruísmo absoluto e perfeito) - por conta própria acerca das opções e escolhas que podem conduzir à felicidade ou produzir dor; decidir-se por normas, instituições, sistema de eticidade, etc. Decisões nas quais se oculta a probabilidade imensurável de erro. Entretanto,

Deve decidir - mesmo intersubjetivamente - no espaço ambíguo entre $a$ ) o conhecimento e a pulsão perfeitos (impossíveis); e $b$ ) a negação clara da vida (impossível eticamente). Entre ambos os extremos, abre-se todo o âmbito do conhecimento e da pulsão finitos, imperfeitos, nos quais se encentra $a$ possibilidade do erro (prático e teórico como "totalização" do sistema sobre a realidade da vida), do egoísmo pulsional determinado pela 
autorreferencialidade dos instintos de autoconservação sob o princípio de morte; numa palavra, do "mal". Esse tipo de "mal" toma-se fundamento de escolhas de mediações que geram vítimas, em grande parte não intencionais, que se acumulam na história; é nosso tema. $\mathrm{O}$ mal se descobre pela inversão sofrida pelo sistema de eticidade vigente, estabelecido, ou pelas normas, ações, instituições, etc., que, apesar de pretenderem cumprir com os princípios éticos para fazer o "bem" [...], causam não obstante vítimas. O mal é a origem oculta que causa vitimação (e o faz a partir do sentido comum tradicional dos grupos dominantes e a partir da própria ciência social não-crítica, como a de Weber ou Popper, criticada esta última por Adorno na conhecida polêmica). (DUSSEL, 2012 , p. 376 - grifos do autor).

Vimos, anteriormente, que o reconhecimento da vítima se configura - de maneira positiva, como juízo de fato (“Há uma vítima!") - na primeira condição de possibilidade para o início do processo crítico (Cf. item "2.2” deste trabalho). Agora, com referência ao princípio ético-crítico, o reconhecer a vítima remete - negativamente - à passagem do juízo de fato do critério ("Há uma vítima!") para o juízo normativo (o princípio crítico). Momento fundamental da Ética da Libertação. Em vista da melhor compreensão do tema, será importante retrocedermos até a questão da fundamentação da verdade prática universal, demonstrada por Dussel (cuja possiblidade se mostrará necessária à posterior fundamentação do princípio éticocrítico material, do qual nos ocupamos neste instante).

No primeiro capítulo ("O momento material da ética. A verdade prática”) da Ética da Libertação, Dussel (2012) se propõe a reformular o sentido de uma ética material - contra a tradição filosófica que, desde Kant, afirma a impossibilidade de uma verdade prática universal - e, desse modo, poder demonstrar a possibilidade de definição de enunciados normativos (o “deve ser”) a partir dos enunciados de fato (o “é”), com pretensão de verdade prática, no âmbito da razão prático-material.

Assim, de acordo com Dussel, o critério material universal da ética - que põe a obrigatoriedade da produção, reprodução e desenvolvimento da vida humana concreta de todos os sujeitos éticos (enquanto sujeitos humanos vivos) participantes da comunidade de vida - é, simultaneamente, um critério de verdade prática e teórica. E sua condição de universalidade decorre do fato de estar inscrito no "modo de realidade do sujeito ético" (o âmbito do "real", da vida do sujeito ético corporal vivo), nível de ação da razão prático-material e da razão éticooriginária; de enunciados ou juízos de fato (a partir dos quais, agora, pretende demonstrar a possibilidade de juízos éticos materiais e normativos; com pretensão de verdade prática):

Aquele que atua humanamente sempre e necessariamente tem como conteúdo de seu ato alguma mediação para a produção, reprodução ou desenvolvimento autorresponsável da vida de cada sujeito humano numa comunidade de vida, como cumprimento material das necessidades de sua corporalidade cultural (a 
primeira de todas o desejo do outro sujeito humano), tendo por referência última toda a humanidade. (DUSSEL, 2012, p. 134 - grifos do autor)

Dussel enfrenta a problemática acerca da possibilidade de fundamentação de enunciados normativos a partir dos enunciados descritivos, ou seja, a fundamentação da verdade prática universal, em vista do que se faz necessário evitar o erro formal já previsto, da impossibilidade lógica. Demonstrar a possibilidade desta passagem torna-se, portanto, imprescindível para o momento de fundamentar o princípio ético-crítico material da Ética da Libertação. Dussel desenvolve sua argumentação de maneira expositiva, demonstrando que tal passagem ocorre por um processo de fundamentação dialético-material - de um enunciado descritivo/juízo de fato a outro, ao nível material da razão prático-material, transversalmente - e não por um processo formal dedutivo (ou seja, sem deduzir do critério formal o princípio material normativo), por meio do que escapa à chamada "falácia naturalista".

Isto é, a produção, reprodução e desenvolvimento da vida de cada sujeito humano é ela mesma um fato (sobre o qual podem ser feitos "juízos de fato" ou "enunciados descritivos"; não meramente da razão analítico-formal ou instrumental), que se "impõe" à própria vontade (à ordem pulsional da humanidade como gênero, da comunidade e a cada sujeito ético) por sua inevitável constituição autorreflexiva. A vida humana não só se dá espontaneamente, mas nos é imposta a nós mesmos como uma "obrigação" sua conservação e desenvolvimento. Quer dizer, sobre o "há vida humana" pode-se "fundamentar" (racional, prático-material e reflexivamente) o dever-ser ético (que pode ser emitido como "enunciado normativo" ou "juízos éticos de realidade"), com pretensão de verdade, como exigências deônticas de produzir, reproduzir e desenvolver a própria vida do sujeito ético. A partir do ser-vivente do sujeito humano pode-se fundamentar a exigência do dever-ser da própria vida, e isto porque a vida humana é reflexiva e autorresponsável, contando com sua vontade autônoma e solidária para poder sobreviver [...] $\mathrm{O}$ viver transforma-se assim de um critério de verdade prática numa exigência ética: no dever-viver. (DUSSEL, 2012, p. 141 - grifos do autor)

Dessa maneira, a realidade concreta do sujeito ético (âmbito material da vida) se desvela como sendo "o âmbito universal" com referência à vida humana com relação ao qual "todas as culturas são concreções particulares, conformadas por dentro pelo referido critério universal material da necessidade de produzir, reproduzir e desenvolver a vida humana como tal (em toda a humanidade e sempre)" (DUSSEL, 2012, p. 135 - grifos do autor).

Bem, tendo recuado um passo, já podemos retornar ao ponto no qual nos detivemos para avançar com maior segurança. Agora, no momento ético-crítico, a responsabilidade marca a passagem do veto ao "outro" (veto que o impede de se tornar "ser-vivente") à afirmação do direito da vítima à vida. A vítima, entretanto, não é o "outro" a quem se reconheça como um 
igual sujeito ético. O caráter ético-crítico do ato de responsabilidade consiste exatamente em assumir a vida do "outro" como vítima, como Outro (razão ético-pré-originária):

Este "tomar a cargo" a vida negada do outro não teria sentido ético se procedesse de um re-conhecimento do outro como igual. $\mathrm{O}$ ato propriamente crítico-ético se origina pelo fato da negatividade do outro re-conhecido como outro: porque é uma vítima; porque tem fome; porque não pode obter benefício algum de sua existência: gratuidade da re-sponsabilidade. Muito pelo contrário, está me pedindo solidariedade a partir da "exposição" de sua própria corporalidade sofredora. Pede-me, suplica-me, ordena-me eticamente que o ajude. (DUSSEL, 2012, p. 378 - grifos do autor).

Para Dussel, a gratuidade da responsabilidade pelo outro, como vítima, é um "mandato" (como o define Lévinas em sua metafísica do rosto). Existirá sempre, não resta dúvida, a alternativa por seu não cumprimento. O mandato, entretanto, antecede a decisão, de modo que - favorável ou não - o sujeito ético não estará isento de sua responsabilidade:

se não assumo a re-sponsabilidade não deixo de ser por isso responsável pela morte do outro, que é minha/nossa vítima, e de cuja vitimação sou/somos causa cúmplice, pelo menos por ser um ser humano, destinado à responsabilidade comunitária da vulnerabilidade compartilhada de todos os viventes. Sou/somos re-sponsável/veis pelo outro pelo fato de ser humano, "sensibilidade" aberta ao rosto do outro. (DUSSEL, 2012, p. 378)

Anteriormente, como vimos acerca da ética material - âmbito de ação da razão práticomaterial, de verdade prática -, o princípio material normativo determina o dever de todo sujeito ético agir responsavelmente por sua própria vida. Agora, no momento ético-crítico material âmbito de ação da razão prático-material crítica (mas que também poderá agir a razão éticopré-originária) que, a partir das vítimas toma consciência da não-verdade do sistema - o enunciado normativo crítico trata da responsabilidade pela vida negada do outro:

porque devo produzir, reproduzir e desenvolver a vida humana em geral, há razão para reproduzir a vida negada da vítima de um sistema opressor. Trata-se da negação ética de uma negação empírica. A passagem por fundamentação do juízo de fato ("Há uma vítima!") para o juízo normativo ("Devo responsavelmente tomá-la a cargo e julgar o sistema que a causa!") é agora justificável (DUSSEL, 2012, p. 379).

Enfim, o princípio ético-crítico da Ética da Libertação, tendo por sujeito a própria comunidade das vítimas, pode ser enunciado nos seguintes termos:

Os que agem ético-criticamente re-conheceram a vítima como ser humano autônomo, como o Outro como outro que a norma, ato, instituição, sistema de eticidade, etc., ao qual se negou a possibilidade de viver (em sua totalidade ou em algum de seus momentos); de cujo re-conhecimento simultaneamente se descobre uma co-responsabilidade pelo outro como vítima, que obriga a tomála a cargo diante do sistema, e, em primeiro lugar, criticar o sistema (ou aspecto do sistema) que causa esta vitimação. (DUSSEL, 2012, p. 380 - grifos do autor) 
O aspecto ético-crítico positivo remete ao imperativo da transformação das causas que originam a vítima - e está fundado, de acordo com o nosso filósofo, na famosa "Tese 11", de Marx (Teses sobre Feuerbach). Isto porque não é suficiente que a consciência ético-crítica, responsavelmente, reconheça a existência da vítima se ela permanece negada. "A responsabilidade entra em jogo como ‘crítica’ e ‘transformação’ das causas que originam a vítima como vítima" (DUSSEL, 2012, p. 381).

Para o sujeito ético-crítico, comprometer-se com essa transformação é uma obrigação ética, pelo que é seu dever atuar no sentido de apoiar a realização da vida das vítimas, no cumprimento do dever da crítica (a produção, reprodução e o desenvolvimento da vida de todo sujeito ético na comunidade de vida). Dentre as exigências postas pelo critério da crítica, o "desenvolvimento" da vida não é meramente um adendo. Com relação ao dever de favorecer o desenvolvimento, Dussel (2012) intui um "progresso qualitativo" (enquanto princípio ético) cujos critérios definidores - com referência ao conceito de sustentabilidade e não apenas o quantitativo, tecnológico e produtivista - o tornam distinto do "progresso da modernidade".

\section{Considerações finais}

Vimos, em relação à Ética da Libertação, apenas o seu critério e princípio críticomaterial, a partir da perspectiva limitada do "interior" do momento material da ética, de onde com o nosso filósofo - nos "deslocamos" para um nível acima (mas ainda material), ou seja, a nossa reflexão ficou delimitada ao nível ético-crítico material.

Na Ética da Libertação, o momento material da ética se articula, em alto nível de complexidade, com o formal e o factível para constituir, por subsunção, o nível ético-crítico com critérios e princípios próprios - que, igualmente será material, formal e de factibilidade, entretanto, agora a partir da negatividade das vítimas. Neste sentido, não obstante a relevância do momento formal e factível, como Dussel demonstra em sua Ética, é no âmbito material, em primeiro lugar, que se revela a "vítima", como vida negada, em sua corporalidade atingida.

Assim, a "vítima" aparece como a principal categoria crítica da Ética da Libertação; categoria na qual convergem o conteúdo (as condições concretas de produção, reprodução e desenvolvimento da vida) e perspectiva (o "negativo", como vida negada). Nesta medida, a "vítima" torna possível a passagem dialética do âmbito real-concreto (o modo da vida humana) ao nível abstrato e teórico da norma ético-crítica (o dever ser). Esta dialética da vítima é possível graças a uma segunda categoria de igual relevância, a "corporalidade". 
A Ética da Libertação é uma ética da vida. Ética crítica a partir da vítima como corporalidade negada, a partir da qual será possível a superação da moderna metafísica do sujeito (como substância descorporificada) e, ao mesmo tempo, afirmar um certo tipo de sujeito-histórico (enquanto intersubjetividade comunitária das vítimas), a partir do qual se pode criticar tanto os "sujeitos-coletivos substantivados" quanto a "impessoalidade" sistêmica e epistemológica de algumas correntes da filosofia contemporânea.

Por outro lado, a "vítima" atualiza a intuição originária da Filosofia da Libertação, sob inspiração levinasiana. Primeiramente, o "outro" foi subsumido na construção da econômica juntamente com a contribuição do aporte da crítica marxiana. Posteriormente, no contexto do debate com a Ética do Discurso, será incorporado na comunidade real de vida, da pragmáticaeconômica. É neste novo contexto teórico e categorial que Dussel intuirá a comunidade real das vítimas, intersubjetividade comunitária, enquanto o novo sujeito-histórico (comunitário nãosolipsista) responsável pela aplicação do princípio ético-crítico de libertação - vemos Lévinas, Marx e Apel subsumidos de maneira bastante pessoal, crítica e criativa por Dussel na arquitetônica da Ética da Libertação.

Por tudo isso, temos a centralidade e a relevância do aspecto material-negativo da Ética da Libertação. Ademais, o critério e princípio crítico-material mobilizam o racional e a sensibilidade no processo de desenvolvimento da consciência ético-crítica. São os diversos níveis de racionalidade mobilizados na definição do critério e na aplicação do princípio; é a sensibilidade que ativa o reconhecimento da vítima como corporalidade-vulnerável, face à qual surge o dever da responsabilidade solidária pela vida da vítima e por suas lutas de libertação.

\section{REFERÊNCIAS BIBLIOGRÁFICAS}

BEORLEGUI, Carlos. Historia del pensamiento filosófico latinoamericano: una búsqueda incesante de la identidad. 3. ed. Bilbao: Universidad de Deusto, 2010. (Serie Filosofía, v. 34).

Diálogo de éticas: entre la Ética del Discurso (Apel) y la Ética de la Liberación (Dussel). In: Estudios de Deusto, Facultad de Derecho de la Universitad de Deusto, Bilbao, v. 45, n. 1, Jan./Jun., 1997, p. 67-95. Disponível em: <http://revistaestudios.revistas.deusto.es/article/view/604/766>. Acesso em: 04 Jun. 2019.

DUSSEL, Enrique. En búsqueda del sentido. Sobre el origen y desarrollo de una Filosofía de la Liberación. Buenos Aires: Editorial Las cuarenta, 2018a. (Colección Obras completas de Enrique Dussel).

Autopercepción intelectual de un proceso histórico. In: DUSSEL, E. En búsqueda del sentido. Sobre el origen y desarrollo de una Filosofía de la Liberación. Buenos Aires: Editorial Las cuarenta, 2018b. (Colección Obras completas de Enrique Dussel), p. 15-75. 
Ética da libertação: na idade da globalização e da exclusão. 4. ed. Tradução de Ephraim Ferreira Alves; Jaime A. Clasen; Lúcia M.E. Orth. Petrópolis: Editora Vozes, 2012.

. Ética del discurso y ética de la liberación. Madrid: Editorial Trotta, 2005. (Colección Estructuras y Procesos. Serie Filosofía).

La ética de la liberación ante el desafio de Apel, Taylor y Vattimo. Ediciones de la Universidad Autónoma del Estado de México: Cidade do México, 1998.

. Debate en torno a la Ética del Discurso de Apel. Diálogo filosófico Norte-Sur desde América Latina. Ciudad de México: Siglo XXI; UAM-Iztapalapa, 1994a.

Ética de la liberación (hacia el "punto de partida" como ejercício de la "razón ética originária"). In: SIDEKUM, Antonio (Org.). Ética do Discurso e Filosofia da Libertação: modelos complementares. São Leopoldo-RS: Editora UNISINOS, 1994b, p. 145-170.

Las metáforas teológicas de Marx. Navarra-Es: Editorial Verbo Divino, 1993a.

. Apel, Ricoeur, Rorty y la filosofia de la liberación: con respuestas de Karl-Otto Apel y Paul Ricoeur. Guadalajara: Universidad de Guadalajara, 1993b. (Colección Fin de Milenio)

Del escéptico al cínico. (Del oponente de la ética del discurso al de la filosofía de la liberación). In: DUSSEL, E. Apel, Ricoeur, Rorty y la filosofia de la liberación: con respuestas de Karl-Otto Apel y Paul Ricoeur. Guadalajara: Universidad de Guadalajara, 1993c, p. 84-95. (Colección Fin de Milenio)

Filosofia da Libertação. Tradução: Luiz João Gaio. 2. ed. São Paulo: Loyola; Piracicaba-SP: UNIMEP, 1977. (Coleção Reflexão Latino-americana, Filosofia na América Latina, vol. 3, tomo I).

SIDEKUM, Antonio (Org.). Ética do Discurso e Filosofia da Libertação: modelos complementares. São Leopoldo-RS: Editora UNISINOS, 1994. 